\title{
Effects of inferior splenic lobe pole fixation and gastrosplenic peritoneal membrane section on the vitality of the remanent of subtotal splenectomy in rats $^{1}$
}

\author{
Fernanda Alves Mendonça', Felipe Poubel Timm do Carmo ${ }^{\text {II }}$, Louise Goncalves Paris ${ }^{\text {III }}$, Marya Duarte Pagotte ${ }^{\mathrm{IV}}$, Fernanda \\ Lube Antunes Pereirav, Paula Vieira Teixeira Vidigal ${ }^{\mathrm{VI}}$, Danilo Nagib Salomão Paulo ${ }^{\mathrm{VII}}$, Tarcizo Afonso Nunes ${ }^{\mathrm{VIII}}$
}

\author{
DOI: http://dx.doi.org/10.1590/S0102-865020150070000003
}

IFellow Master degree, Postgraduate Program in Surgical and Ophthalmological Applied Sciences, Universidade Federal de Minas Gerais (UFMG), Belo Horizonte-MG, Brazil. Intellectual and scientific content of the study, acquisition and interpretation of data, manuscript preparation.

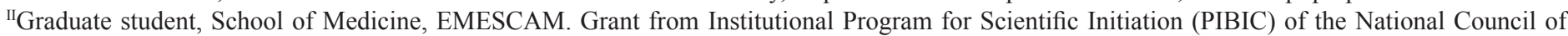
Scientific and Technological Development (CNPq) Ministry of Science, Technology and Inovation, Brazil. Surgical procedures.

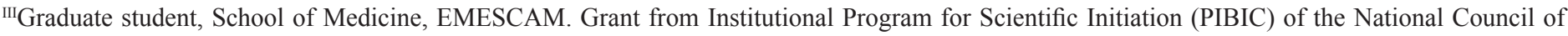
Scientific and Technological Development (CNPq) Ministry of Science, Technology and Inovation, Brazil. Acquisition of data.

${ }^{\text {IV }}$ Graduate student, School of Medicine, EMESCAM. Grant from Institutional Program for Scientific Initiation (PIBIC) of the National Council of Scientific and Technological Development (CNPq) Ministry of Science, Technology and Inovation, Brazil. Technical support of the study.

${ }^{v}$ Graduate student, School of Medicine, EMESCAM. Grant from Institutional Program for Scientific Initiation (PIBIC) of the National Council of Scientific and Technological Development (CNPq) Ministry of Science, Technology and Inovation, Brazil. Surgical procedures, acquisition of data.

${ }^{\mathrm{VI}} \mathrm{PhD}$, Chairman, Full Professor, Department of Pathology, UFMG, Belo Horizonte-MG, Brazil. Histological examinations.

${ }^{V I I P h D}$, Chairman, Full Professor, Department of Surgery, College of Health Sciences, EMESCAM, Vitoria-ES, Brazil. Conception, design, intellectual and scientific content of the study; statistical analysis; manuscript writing; critical revision.

${ }^{\mathrm{VIII}} \mathrm{PhD}$, Chairman, Full Professor, Department of Surgery, Medical School, UFMG, Belo Horizonte-MG, Brazil. Manuscript writing, critical revision.

\begin{abstract}
PURPOSE: To investigate the vitality of the spleen lower pole after subtotal splenectomy with suture to the stomach and after posterior peritoneal gastro-splenic membrane section, using macro and microscopic evaluations.

METHODS: Sixty Wistar rats were used in this study and were randomly distributed in the three groups: Group 1: $(\mathrm{n}=20)$, subtotal splenectomy with lower pole preservation, Group 2: $(\mathrm{n}=20)$ subtotal splenectomy with lower pole preservation and suture to the stomach, Group 3: subtotal splenectomy with lower pole preservation and posterior peritoneal gastrosplenic ligament section. The animals were sacrificed 45 days after the surgery and the spleen lower poles were removed for macroscopic and microscopic examination.

RESULTS: All animals in this series survived. No macroscopic differences were encountered between the groups. Microscopic evaluation observed statistic difference concerning fibrosis between group 1 and $3(\mathrm{p} \leq 0.05)$, but the analysis for necrosis and inflammation presented no differences.
\end{abstract}

CONCLUSION: Vitality of the spleen lower pole after subtotal splenectomy is minimally modified when it is fixed to the stomach or when the posterior peritoneal gastrosplenic ligament is resected.

Key words: Spleen. Splenectomy. Surgery. Splenic Diseases. Rats, Wistar. 


\section{Introduction}

Until the middle of the 50's, surgeons performed total splenectomy no matter the severity of the disease or the spleen's trauma, once it was considered an organ with no functional importance $^{1,2}$.

In 1952, fulminant sepsis was detected in the postoperative period of five children who had undergone total splenectomy by spherocytosis ${ }^{3}$. Since then, studies have been carried out to clarify infection risks after splenectomy, at the same time, to reevaluate technical indications and splenectomy techniques ${ }^{4,5}$.

The sepsis that has its onset after the spleen's removal may occur not only in children but also in adults and may initiate any time after the operation. Patients who underwent splenectomy have a $5 \%$ risk of developing sepsis in the course of their lives, no matter the surgical indication ${ }^{5}$.

Sepsis may occur immediately after splenectomy or many years after it. However, it occurs more often in the first two years (50\% to $70 \%$ of all cases and up to $80 \%$ in children $)^{5-7}$. Infectious complications were also reported in animals used in experiments ${ }^{8,9}$.

Individuals submitted to the spleen's total section are subject to other complications besides sepsis, considering that the spleen is an organ of the mononuclear phagocyte system that plays an important role in the immunologic system, mainly in the synthesis of complementary factors and immunoglobulins. Some of these complications may occur in Gaucher's, myeloid metaplasia ${ }^{10,11}$. Alterations in lipid metabolism were detected in humans and in laboratory animals that may cause atherosclerosis ${ }^{12-16}$.

Considering the risks inherent to total splenectomy, the spleen's partial preservation is recommended ${ }^{7,10,11,17-20}$.

In 1959, Campus Christo introduced partial splenectomy in surgical practice ${ }^{21}$. This author stated that the vascular architecture of the splenic pedicle facilitates the section of any spleen segment and the preservation of the rest of the organ. After this study, surgery partially preserving the spleen became more frequent.

Subtotal splenectomy with the preservation of the spleen's superior pole for the surgical treatment of schistosomic portal hypertension was proposed by Petroianu in 1979. This author verified experimentally and in anatomical studies that the spleen's superior pole did not depend of the splenic pedicle, because the splenogastric vessels were sufficient to irrigate this segment of the organ. This way, subtotal splenectomy could be done, even in cases when the main vessels need to be clamped ${ }^{10}$.

Of all surgical procedures, the most recently described was subtotal splenectomy with the preservation of the inferior pole (ESTPI). This surgery was performed in dogs and rats and it was verified that blood supply occurred through the vessels of the gastrosplenic ligament that was still viable and its functions were preserved ${ }^{22-25}$. ESTPI was also experimentally done with laparoscopy, being feasible in $100 \%$ of the cases and the viability of spleen's inferior pole in $94,1 \%$ of the cases ${ }^{26}$.

In a study to evaluate the spleen's inferior pole before and after hyperbaric oxygen therapy ${ }^{27}$, this structure was fixed to the stomach to avoid torsion. However, high incidence of splenic necrosis occurred.

Based on these observations, hypotheses were raised whether the fixation of the spleen's inferior pole to the stomach might contribute to this complication, possibly caused by vascular pedicle torsion of the splenic segment. Besides, it was questioned whether the complete sectioning of the peritoneal gastrosplenic membrane might interfere in the vitality of these remains because this membrane seems to have the function of fixing the spleen's inferior pole and its sectioning might contribute to its torsion, ischemia and necrosis.

The present study's purpose is to verify the vitality of the spleen's inferior pole, after subtotal splenectomy with the preservation of the inferior pole, with or without its fixation in the stomach and the total section of the peritoneal gastrosplenic membrane.

\section{Methods}

The study was approved by Ethics Committee in Animal Experimentation at EMESCAM (protocol 001/2011-CEUA) and Universidade Federal de Minas Gerais UFMG (protocol 211/2012-CETEA).

The study was performed in 60 Wistar male rats, weighing between $280 \mathrm{~g}$ and $320 \mathrm{~g}$, at the Laboratory of Animal Experimentation of the Research Center at EMESCAM. The animals were kept in adequate cages of three animals each, dully identified and maintained in STD 5 Vivarium Cabinet (Vidy Group - São Paulo, Brazil) under the species adequate conditions such as temperature of 20 to $22^{\circ} \mathrm{C}$, ventilation and luminosity (12 hours light and 12 hours dark) control. The animals received adequate rat food (Nuvilab CR-1 autoclavable - Nuvital ${ }^{\circledR}$ ) and water ad libitum in all phases of the study. The animals were identified by cage number and by tail marking.

\section{Animal group composition}

The 60 rats were randomly distributed in three groups: Group 1 (G1) - ESTPI control (n=20), Group 2 (G2) - ESTPI with the 
spleen's inferior pole fixed in the gastric body (n=20), Group 3 (G3) - ESTPI with sectioned peritoneal gastrosplenic membrane $(n=20)$.

\section{Surgical procedures}

After six hour fast, the animals were weighted (Filizola electronic scale MF-6 model - 1g sensitivity) and anesthetized with ketamine chlorohydrate ( Vetaset $^{\circledR}$, Fort Lodge - Iowa, USA) $50 \mathrm{~g} / \mathrm{mg} / \mathrm{Kg}$ associated to xylazine chlorohydrate (Kensol, König - Avellaneda, Argentina) at $5 \mathrm{mg} / \mathrm{Kg}$ intraperitoneal injection. After this, the animals were immobilized on the surgical table, and the abdominal and thoracic wall was shaved, beginning $0.5 \mathrm{~cm}$ above the xiphoid process and ending on the pelvic region. The abdominal wall assepsia was done with polyvynilpyrrolidone iodine. Surgical procedure in group 1: ESTPI, followed by a) median incision (approximately $2.5 \mathrm{~cm}$ long) on the skin and subcutaneous tissue, beginning $0.5 \mathrm{~cm}$ bellow the xiphoid process with scalpel blade; $b$ - Opening of linea alba and peritoneum ; c) examination of the abdominal cavity; d) mobilization of the spleen up to the surface of the abdominal cavity; e) Two or three clampings were done as well as the sectioning of the vessels that irrigated the spleen's superior and median segments, close to the splenic surface, with mononylon 6.0 (Shalon Fios Cirúrgicos LTDA- Goiás, Brasil.), f) sectioning of the spleen bellow the clamped vessels, with the inferior pole irrigated by the vessels of the gastrosplenic ligament 22 ; g) - sectioning of the gastrosplenic peritoneal membrane that was posteriorly situated bellow the gastrosplenic ligament (vascular pedicle). This membrane is thin, avascular, transparent, and is situated from the posterior rim of the spleen to the stomach (Figure 1A, B); h) The bleeding area of the spleen's inferior pole was not sutured; i) measuring of the spleen's inferior pole on its central part as to its length, width and thickness using digital paquimeter (Zaas Precision, Amatools, Piracicaba/SP, Brasil); j) Abdominal cavity synthesis by continuous suture in one plane, using mononylon 6.0 (Shalon $^{\circledR}$, Shalon fios Cirúrgicos LTDA Goiás, Brasil).

Group 2 surgical procedure: a) ESTPI was carried out as described in group1; b) suture of the spleen's inferior pole to the gastric body using simple 6.0 mononylon stitches $\left(\right.$ Shalon $^{\circledR}$, Shalon Fios Cirúrgicos LTDA - Goiás, Brasil) that involved the seromuscular layer of the gastric body and a small portion of the splenic parenchyma; c) excessive traction of the spleen's inferior pole was avoided in the cranial direction in order to keep it nearest to its anatomical position (Figure 1C).

Group 3 surgical procedure: ESTPI was carried out as described in group1, followed by total sectioning of the peritoneal gastrosplenic membrane (Figure 1D).
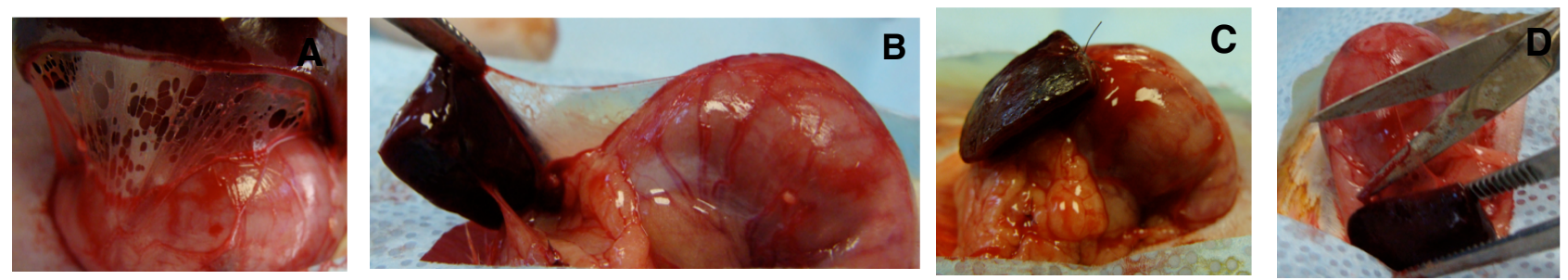

FIGURE 1 - (A) Peritoneal gastrosplenic membrane, (B) Peritoneal gastrosplenic membrane after ESTPI, (C) Inferior pole of the spleen fixed to the stomach (group 2), (D) Sectioning of the gastrosplenic membrane on the spleen's inferior pole (group 3).

After the surgical procedures, $5 \mathrm{ml}$ of $0,9 \%$ saline solution was administered on the animal's subcutaneous. The spleen's superior portion was removed and its width, length and thickness were measured with a digital paquimeter and, afterwards, it was photographed, weighed, sandpapered in neutral buffered $10 \%$ formalin (hydrogenic potential - $\mathrm{pH}$ ) and processed in paraffin for histological control of the spleen's inferior pole vitality.

\section{Postoperative period}

After the surgical procedures, the animals were kept in individual cages and received a $52,5 \mathrm{mg}$ /day dose of dypirone diluted in $600 \mathrm{ml}$ water from the animal drinking fountain (6 drops for each $100 \mathrm{ml}$ of water, for 72 hours). After this period, the animals were daily monitored.

\section{Animal reoperation and euthanasia}

On the 45th day of the postoperative period, the rats of all groups were weighted, anesthetized as described at the beginning of this study and laparotomized for the macroscopic evaluation of the spleen's remnants and of the peritoneal cavity, followed by the sectioning of the spleen's inferior pole for microscopic evaluation. Next, the animals were euthanized with a lethal dose 
of thiopental sodium - Thiopentax (Cristália Laboratory) in the peritoneal cavity $(100 \mathrm{mg} / \mathrm{Kg})$ and intracardiac potassium chloride (Farmace). The spleen's inferior poles, as soon as they were removed, were again measured (width, length end thickness) in its central part with the help of a digital paquimeter and weighted in an Adventurer OHAUS ${ }^{\circledR}$ scale model AR 3130 with $0.001 \mathrm{~g}$ precision, analyzed macroscopically, photographed and fixed in $10 \%(\mathrm{pH} 7)$ neutral buffered formalin solution and processed in paraffin for microscopic analysis.

\section{Macroscopic evaluation of the spleen's inferior pole}

The evaluated macroscopic aspects were: coloration, form, size, the aspect of the spleen's inferior pole surface, presence of necrotic or fibrotic tissue and adherences. The aspect which was more similar to the characteristics of the spleen's superior portion removed in the ESTPI was considered normal: reddish-purple coloration, soft consistency, flat and brilliant surface, absence of necrotic and fibrotic tissues. In this analysis, a longitudinal incision of the spleen's inferior pole was done to amplify the surface under observation.

\section{Microscopic evaluation of the spleen's inferior pole}

Microscopy was done by a pathologist who did not know to which group the animal belonged. The fragments of the spleen's superior segment and the inferior pole were included in $3 \mu \mathrm{m}$ thickness paraffin blocks and stained with hematoxylineosin. The analysis was done under general overview of the slide blade using a DMLB Leica microscope, with 50, 100, 200 and x400 magnifications.

Necrosis was considered as loss of the usual architecture of the splenic parenchyma with its substitution for amorphous eosinophillic material. Each slide was examined as to the percentage of necrosis affected area and it was considered minimal microscopic alteration (1) when $33 \%$ of the examined field was affected; moderate (2) when the affected area was $66 \%$ of its total, and intense (3) when the area was more than $66 \%$ affected. The splenic parenchyma without any alteration was classified as normal (0).

Inflammatory infiltrate was defined as the increased number of inflammatory cells distributed in the analyzed area and classified as absent (0), minimum (1), moderate (2) and intense (3). Vascular proliferation - presence of vascular neoformation in areas of granular tissue- was classified as absent (0), minimum (1), moderate (2) and intense (3). Fibrosis was considered as the deposition of thick collagen fibers substituting the usual splenic parenchyma and classified as absent (0), minimum (1), moderate (2) and intense (3), according to the intensity of the findings in the analyzed area of the of the spleen's inferior pole.

\section{Studied variables and statistical tests}

Statistic calculation was done with Biostat 5.0 program. Student's t test was used to compare the animals' weight from the beginning to the end of the experiment for related samples. Student's t test was also used to compare the length, width and thickness of the spleen's inferior pole, from the beginning to the end of the experiment; ANOVA was used to compare the collected data among the groups from the beginning and end of the experiment. Kruskal Wallis test was used to compare the median necrosis percentage of the spleen's inferior pole in the three groups. Fisher's exact test was used to compare microscopic necrosis frequency and degrees of necrosis among the three groups. Fisher's exact test was used to evaluate the frequency of microscopic fibrosis among the three groups. The value $\mathrm{p} \leq 0.05$ was considered significant.

\section{Results}

In the course of the experiment, none of the animals died. The rats medium weight in the pre-operative period was $345.53 \pm$ 28.66 and in the postoperative period $448.63 \pm 31.22(\mathrm{p}<0.0001)$. Therefore, the animals presented significant weight gain in the preoperative period and on the 45th day of the postoperative period.

\section{Inferior pole of the spleen's macroscopic analysis}

Adherences were found between the spleen's inferior poles and the neighboring structures in all animals, independently of the group. In group 1, in 17 (85\%) animals the spleen's inferior poles were apparently normal, similar to the superior poles used as reference (Figure 2A, B) with epiplon adherences. In the other three cases $(15 \%)$, the adherences involved the liver, stomach and omentum, and the macroscopic aspect was altered with size reduction, form (roundish) and whitish spleen surface (Figure $2 \mathrm{C}, \mathrm{D})$.

The aspect of the spleen's inferior pole was normal in $95 \%$ of the cases in Group 2. Only one case presented macroscopic alterations with size reduction, whitish external surface and adherence to the liver and stomach. In group 3, the spleen's inferior 
pole had an apparent normal aspect in $16(80 \%)$ cases. In the other $4(20 \%)$ cases there was size reduction of the spleen's inferior pole and adherences in the stomach and omentum (Figure 2). There was no significant difference in the percentage of macroscopic alterations among the three groups $(\mathrm{G} 1 \mathrm{x}$ G2 $\mathrm{p}=0.60 ; \mathrm{G} 1 \mathrm{xG} 3 \mathrm{p}$ $=1.00 ; \mathrm{G} 2 \mathrm{xG} 3 \mathrm{p}=0.34$ ) (Table 1).
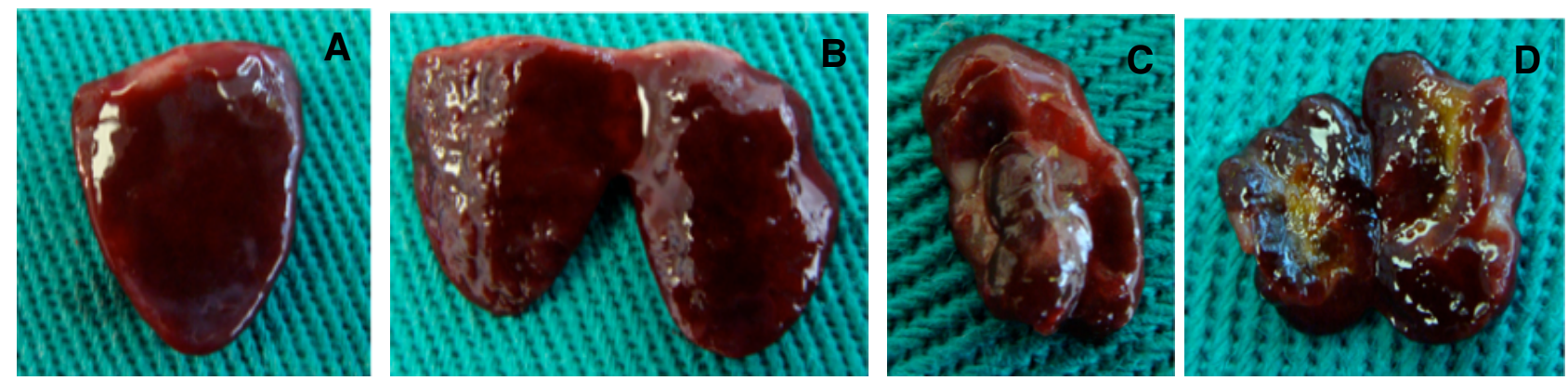

FIGURE 2 - Spleen lower pole, macroscopic analysis. (A) normal aspect, (B) longitudinal incision with normal aspect, (C) size and form alterations and (D) intense fibrosis.

TABLE 1 - Macroscopic aspects of the spleen inferior pole in rats after subtotal splenectomy ( $\mathrm{n}=60)$ (20 animals/group).

\begin{tabular}{cccccc}
\hline Group & \multicolumn{2}{c}{ Macroscopic aspects } & & \\
\hline & Normal & Alterations & $\mathrm{p}$ & $\mathrm{p}^{*}$ & $\mathrm{p}^{* *}$ \\
1 & $17(85 \%)$ & $3(15 \%)$ & & & \\
2 & $19(95 \%)$ & $1(5 \%)$ & 0.60 & & 0.34 \\
3 & $16(80 \%)$ & $4(20 \%)$ & & 1.00 & 0.00 \\
\hline
\end{tabular}

Group 1 (G1) - ESTPI control, Group 2 (G2) - ESTPI with the spleen's inferior pole fixed in the gastric body, Group 3 (G3) - ESTPI with sectioned peritoneal gastrosplenic membrane. Fisher exact test: $\mathrm{p}=\mathrm{G} 1$ vs $\mathrm{G} 2 ; \mathrm{p}^{*}=\mathrm{G} 1$ vs $\mathrm{G} 3 ; \mathrm{p}^{* *}=\mathrm{G} 2$ vs $\mathrm{G} 3$.

The average weight of the spleen's inferior pole in group 1 was $441 \pm 115.2$; in group 2, $421 \pm 116.7$ and, in group 3, $471.7 \pm$ 144.9. ANOVA registered no difference among the average weight of the spleen's inferior pole in all three groups $(p=0.54)$.
The length of the spleen's inferior pole did not present any difference between the initial period of the study and the final period, per animal group or among the groups $(p>0.05)$ (Table 2).

TABLE 2 - Length of the spleen's inferior pole $(\mathrm{mm})$ in rats submitted to subtotal splenectomy on the initial and final period (45 days) $(\mathrm{n}=60)(\mathrm{n}$ animals/group $=20)$.

\begin{tabular}{ccccccc}
\hline Group & \multicolumn{2}{c}{$\begin{array}{c}\text { Inicial } \\
\text { Lenght }\end{array}$} & \multicolumn{2}{c}{$\begin{array}{c}\text { Final } \\
\text { Lenght }\end{array}$} \\
\hline & $\mathrm{AM}$ & $\mathrm{SD}$ & $\mathrm{AM}$ & $\mathrm{SD}$ & $\mathrm{p}$ & $\mathrm{p}^{*}$ \\
1 & 12.47 & 1.92 & 13.30 & 2.42 & 0.11 & $\mathrm{p}^{* *}$ \\
2 & 13.41 & 1.81 & 13.07 & 1.87 & 0.56 & \\
3 & 13.21 & 1.86 & 13.13 & 2.82 & 0.90 & 0.95 \\
\hline
\end{tabular}

Group 1 (G1) - ESTPI control, Group 2 (G2) - ESTPI with the spleen's inferior pole fixed in the gastric body, Group 3 (G3) - ESTPI with sectioned peritoneal gastrosplenic membrane. $\mathrm{p}$ : comparison between the initial and final length in each group, $\mathrm{p}^{*}$ : comparison between the initial and final length for group 1 and $3, \mathrm{p}^{* *}$ : comparison between the initial and final length for group 2 and 3. AM- Arithmetic Mean. SD- Standard Deviation.

There was also no difference as well between the spleen's inferior pole thickness among the three groups at the beginning $(p=0.12)$ and at the end of the experiment $(p=0.65)$ (Table 3$)$.
The width of the spleen's inferior pole was not different among the groups in the beginning of the experiment $(\mathrm{p}=0.58)$ and in the end of the experiment $(\mathrm{p}=0.78)$ (Table 4$)$. 
TABLE 3 - Thickness $(\mathrm{mm})$ of the spleen's inferior pole $(\mathrm{mm})$ in rats submitted to subtotal splenectomy on the initial and final period (45 days) $(\mathrm{n}=60, \mathrm{n}$ animals/group $=20)$.

\begin{tabular}{cccccccc} 
Group & \multicolumn{2}{c}{$\begin{array}{c}\text { Inicial } \\
\text { Thickness }\end{array}$} & \multicolumn{2}{c}{$\begin{array}{c}\text { Final } \\
\text { Thickness }\end{array}$} \\
& $\mathrm{AM}$ & $\mathrm{SD}$ & $\mathrm{AM}$ & $\mathrm{SD}$ & $\mathrm{p}$ & $\mathrm{p}^{*}$ & $\mathrm{p}^{* *}$ \\
1 & 4.43 & 0.60 & 4.07 & 0.74 & 0.100 & & \\
2 & 4.82 & 0.77 & 4.10 & 0.53 & 0.001 & & \\
3 & 4.39 & 0.73 & 3.87 & 1.18 & 0.100 & 0.12 & 0.65 \\
\hline
\end{tabular}

Group 1 (G1) - ESTPI control, Group 2 (G2) - ESTPI with the spleen's inferior pole fixed in the gastric body, Group 3 (G3) - ESTPI with sectioned peritoneal gastrosplenic membrane. $\mathrm{p}$ : comparison between the initial and final thickness in each group, $\mathrm{p}^{*}$ : comparison between the initial and final thickness for group 1 and 3 , $\mathrm{p}^{* *}$ : comparison between the initial and final thickness for group 2 and 3. AM-Arithmetic Mean. SD- Standard Deviation.

TABLE 4 - Width of the spleen's inferior pole $(\mathrm{mm})$ in rats submitted to subtotal splenectomy on the initial and final period (45 days) $(\mathrm{n}=60, \mathrm{n}$ animals/group $=20)$.

\begin{tabular}{|c|c|c|c|c|c|c|c|}
\hline \multirow[t]{2}{*}{ Group } & \multicolumn{2}{|c|}{ Inicial width } & \multicolumn{2}{|c|}{ Final width } & \multirow[t]{2}{*}{$\mathbf{p}$} & \multirow[t]{2}{*}{$\mathbf{p}^{*}$} & \multirow[t]{2}{*}{$\mathbf{p}^{* *}$} \\
\hline & $\mathbf{A M}$ & SD & $\mathbf{A M}$ & SD & & & \\
\hline 1 & 10.05 & 0.85 & 9.73 & 1.62 & 0.37 & & \\
\hline 3 & 9.72 & 1.25 & 9.68 & 1.93 & 0.93 & 0.58 & 0.78 \\
\hline
\end{tabular}

Group 1 (G1) - ESTPI control, Group 2 (G2) - ESTPI with the spleen's inferior pole fixed in the gastric body, Group 3 (G3) - ESTPI with sectioned peritoneal gastrosplenic membrane. $\mathrm{p}$ : comparison between the initial and final width in each group, $\mathrm{p}^{*}$ : comparison between the initial and final width for group 1 and 3 , $\mathrm{p}^{* *}$ : comparison between the initial and final width for group 2 and 3. AM-Arithmetic Mean. SD-Standard Deviation.

\section{Microscopic analysis of the spleen's inferior pole}

Minimum necrosis, (affecting up to $33 \%$ of the observed area) occurred in nine (45\%) cases in group 1 , four (20\%) in group
2 and six (30\%) in group 3. There were three cases of moderate necrosis: one in group 1 and two in group 3. Microscopic necrosis frequency was not different among groups 1 and $2(\mathrm{p}=0.10)$, groups 1 and $3(\mathrm{p}=0.35)$ and groups 2 and $3(\mathrm{p}=0.71)$ (Table 5).

TABLE 5 - Microscopic necrosis percentage on the inferior pole of the spleen in rats after subtotal splenectomy ( $\mathrm{n}=60)$.

\begin{tabular}{cccccc}
\hline Group & $\mathbf{n}$ & Necrosis & Normal & $\mathbf{p}$ & $\mathbf{p}^{*}$ \\
\hline 1 & 20 & $9(45 \%)$ & $11(55 \%)$ & & \\
2 & 20 & $4(20 \%)$ & $16(80 \%)$ & 0.10 & 0.35 \\
3 & 20 & $6(30 \%)$ & $14(70 \%)$ & & 0.71 \\
\hline
\end{tabular}

Group 1 (G1) - ESTPI control, Group 2 (G2) - ESTPI with the spleen's inferior pole fixed in the gastric body, Group 3 (G3) - ESTPI with sectioned peritoneal gastrosplenic membrane. Fisher exact test: $p=G 1$ versus $G 2 ; p^{*}=G 1$ versus $G 3 ; p^{* *}=G 2$ versus $G 3$.

Necrosis percentage of the total evaluated area of the spleen's inferior pole varied from $5 \%$ to $40 \%$ in groups 1 and 3 and from $5 \%$ to $30 \%$ in group 2 . Median percentage of necrosis among groups of animals did not differ $(p=0.95)$.

The presence of fibrosis in the spleen's inferior pole was observed in one animal (5\%) in group 1, in two (10\%) in group2, seven $(35 \%)$, in group 3 .

In relation to the degrees of fibrosis in the spleen's inferior pole, only one animal presented degree 2 (moderate) and another one degree 3 (intense), both in group 3. All the other five animals in group 3 presented minimum fibrosis (degree 1).

Fibrosis frequency among groups 1 and 2 was $(\mathrm{p}=1.000)$ and between groups 2 and $3(p=0.064)$ there was no significant difference. However, it was more frequent in group 3 than in group $1(\mathrm{p}=0.022)$ (Table 6).

Only one animal in group 3 presented minimum inflammation (degree 1). This animal was the only one to present moderate necrosis and intense vascular proliferation (degree 3) (Figure 3). 
Effects of inferior splenic lobe pole fixation and gastrosplenic peritoneal membrane section on the vitality of the remanent of subtotal splenectomy in rats

TABLE 6 - Microscopic fibrosis percentage on the spleen inferior pole of rats after subtotal splenectomy $(n=60)$.

\begin{tabular}{cccccc}
\hline Group & $\mathbf{n}$ & $\begin{array}{c}\text { Fibrosis } \\
\text { present }\end{array}$ & $\begin{array}{c}\text { Fibrosis } \\
\text { absent }\end{array}$ & p & $\mathbf{p}^{* * *}$ \\
\hline 1 & 20 & $1(5 \%)$ & $19(95 \%)$ & & \\
2 & 20 & $2(10 \%)$ & $18(80 \%)$ & 1.000 & 0.022 \\
3 & 20 & $7(35 \%)$ & $13(65 \%)$ & & 0.064 \\
\hline
\end{tabular}

Group 1 (G1) - ESTPI control, Group 2 (G2) - ESTPI with the spleen's inferior pole fixed in the gastric body, Group 3 (G3) - ESTPI with sectioned peritoneal gastrosplenic membrane. Fisher exact test: $\mathrm{p}=\mathrm{G} 1$ versus $\mathrm{G} 2 ; \mathrm{p}^{*}=\mathrm{G} 1$ versus $\mathrm{G} 3 ; \mathrm{p}^{* *}=\mathrm{G} 2$ versus $\mathrm{G} 3$.
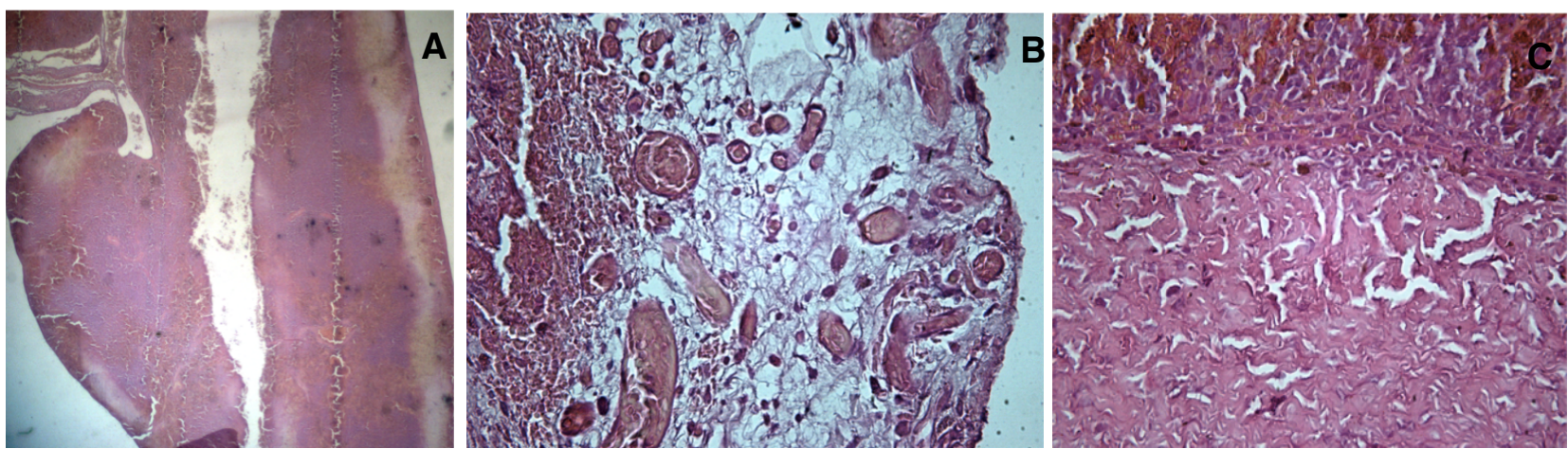

FIGURE 3 - Photomicrography: (A) Moderate necrosis (degree 2). (B) Intense vascular proliferation (degree 3). (C) Intense fibrosis (degree 3). Colored with hematoxylin and eosin, increase of x50 (A) and x400 (B and C).

\section{Discussion}

ESTPI in rats is considered feasible and safe, as described in this study there was no animal death or incidents related to the study. Some ESTPI technical aspects have already been described ${ }^{25}$. This study evaluated two more aspects: the spleen's inferior pole fixation to the stomach and the sectioning of the peritoneal gastrosplenic membrane. The purpose of the study was to evaluate if the technical alterations in the fixation of the splenic remains during ESTPI altered the viability of the splenic parenchyma and to contribute to make this surgery more efficient and safe.

The term peritoneal gastrosplenic membrane used in this study was coined due to the fact that there was no reference to the membrane's name in the literature of rat anatomy. It is a membrane that seems to contribute to the spleen's fixation to the stomach. The hypothesis was that if this membrane were sectioned it could compromise the viability the spleen's inferior pole because the loss of its fixation to the stomach could facilitate torsion and consequently cause ischemia and necrosis.

Based on a previous paper $^{28}$, the 45 th postoperative day was used for animals euthanasia where it was verified that the spleen's remains were histologically similar to the normal splenic tissue in 45 days.
The viability of the spleen's inferior pole, when evaluated macroscopically, was not significantly different in the three groups analyzed. In fact, this structure was macroscopically viable in $85 \%$ in group 1, 95\% in group 2 and $80 \%$ in group 3. These results corroborate previous studies ${ }^{27-29}$.

The thickness of the spleen's inferior pole in group 2 (fixed on the stomach) decreased from the beginning to the end of the experiment and was the only macroscopic finding of statistical significance.

However, one may interpreter that as an isolated finding due to the fact that the width also increased in relation to the other groups, although this is not statistically significant. Besides, the analysis among the groups did not find any difference in the medium weight of the spleen's inferior pole which might induce to the conclusion that the decreased thickness does not interfere with the weight and possibly also with the viability of the above mentioned pole.

It should be emphasized that there was no difference between the length and width of the spleen's inferior pole between the beginning and end of the experiment in each group and in the period pre and postoperative in the three groups of animals.

The presence of adherences in the peritoneal cavity in all cases is an expected finding since they occur due to surgical manipulation, presence of strange bodies (threads, screens, gloves 
powder), dissections and trauma due to tissue heating. This finding was previously mentioned in studies in which the spleen's inferior pole was preserved ${ }^{27-29}$.

It should be remarked that adherences are caused by mesothelium lesions and are detected in five to seven days after the lesion. This is considered normal response to peritoneal healing that begins with coagulation and triggers following events resulting in the formation of fibrin gel matrix. This matrix generates bands which, interposed to two damaged peritoneal areas are the basis of adherence formation. The fibrinolytic system could avoid the formation of fibrin matrices; however, its activity decreases due to surgical trauma ${ }^{30}$.

The macroscopic aspect was altered with volume decrease and firm adherences in the omentum and stomach. One may infer that the alterations detected may be caused either by the spleen's inferior pole vascularization deficit, or by ESTPI technical failure or by the torsion of the vascular pedicle or by its excessive mobility, causing ischemia and vascular necrosis in the splenic parenchyma.

The microscopic analysis showed that there was no difference in the degree of necrosis among the groups of animals. In group 1 minimum necrosis occurred in $89 \%$, in $100 \%$ in group 2 in $66 \%$ in group 3 . Besides, necrosis frequency and medium percentage of necrosis were not significantly different. This suggests that, no matter the technique used (fixation or nonfixation of the spleen's inferior pole, sectioning or non-sectioning of the peritoneal gastrosplenic membrane), the spleen's inferior pole remained viable in more of $80 \%$ of the cases.

Moderate necrosis of the spleen's inferior pole was present in three animals, one in group 1 and two in group 3, but only the animal in group 3 presented inflammation in the microscopic analysis.

When fibrosis is microscopically analyzed, it was observed that it was more frequent in the spleen's inferior pole of group 3 than in group 1, in other words, in the group that suffered the peritoneal gastrosplenic membrane sectioning. It is possible that the area where the membrane was sectioned was a favorable place for adherence and fibrosis formation. These adherences were diagnosed in macroscopic examination of the peritoneal cavity. However, this apparently does not affect the spleen's inferior pole's viability because, in most cases, fibrosis was of minimum degree.

In the study not yet published that motivated this present study (data no show) the viability of the spleen's inferior pole was questioned when it was fixed to the stomach.

This present study showed that the fixation of the spleen lower pole to the stomach, when adequately done, in other words, in the region closest to the anatomical position of the spleen's inferior pole without traction in the cranial direction does not interfere in the viability of inferior pole's remnants from the macro and microscopic point of view.

Besides, the torsion of the spleen's inferior pole was not registered in the group of animals that had undergone peritoneal gastrosplenic membrane sectioning.

According to the results of the study, one can assert that it is up to the surgeon performing ESTPI to decide whether to fix or not the spleen's inferior pole to the stomach or to section or not the peritoneal gastrosplenic membrane. However, it is suggested that, if possible, the peritoneal gastrosplenic membrane should be preserved in order to prevent possible rotation of the spleen's inferior pole and its consequences.

New studies can be carried out to compare other splenopexy techniques. This way, one can evaluate which techniques is more adequate and if others fixation techniques interfere with the viability of the spleen's inferior pole or whether they should be avoided.

\section{Conclusion}

The spleen's inferior pole in rats submitted to ESTPI, did not presented alterations in its vitality when it is fixed on the stomach or when the peritoneal gastrosplenic membrane is sectioned.

\section{References}

1. Cooper MJ, Williamson RC. Splenectomy: indications, hazards and alternatives. Br J Surg. 1984;71:173-80. PMID: 1788795.

2. Feliciano DV, Bitondo CG, Mattox KL, Rumisek JD, Burch JM, Jordan GL Jr. A four-year experience with splenectomy versus splenorrhaphy. Ann Surg. 1985;201:568-75. PMID: 3888130.

3. King H, Shumacker Jr HB. Splenic studies. Ann Surg. 1952;136:23942. PMID: 14953147.

4. Hansen K, Singer DB. Asplenic-hyposplenic overwhelming sepsis: postsplenectomy sepsis revisited. Pediatr Dev Pathol 2001;4:10521. PMID: 11178626.

5. Marques RG, Petroianu A. Infecção fulminante pós-esplenectomia. Arq Gastroenterol. 2003;40:47-54. PMID: 14534666.

6. Morgenstern L, Shapiro SJ. Techniques of splenic conservation. Arch Surg. 1979;114:449-54.PMID: 373704.

7. Resende V, Petroianu A. Subtotal splenectomy for treatment of severe splenic injuries. J Trauma. 1998;44:933-5. PMID: 9603106.

8. Petroianu A, Buzatti KC, Resende V, Sabino KR. Haematological and biochemical characteristics of the splenic effluent blood in schistosomal patients undergoing splenectomy. Rev Col Bras Cir. 2014;41(3):176-80. PMID: 25140648.

9. Morris DH, Bullock FD. The importance of the spleen in resistance to infection. Ann Surg. 1919;70:513-21. PMID: 17864185.

10. Petroianu A. Cirurgias conservadoras do baço para tratamento da doença de Gaucher. Rev Bras Hematol Hemoter. 2004;26:13-8. doi: 10.5581/1516-8424.20130114. 
11. Petroianu A. Subtotal splenectomy for treatment of patients with myelofibrosis and myeloid metaplasia. Int Surg. 1996;81:177-9. PMID: 8912088.

12. Aviram M, Brook JG, Tatarsky J, Levy Y, Carte A. Increased lowdensity lipoprotein levels after splenectomy: a role for the spleen in cholesterol metabolism in myeloproliferative disorders. Am J Med Sci. 1986;291:25-8. PMID: 3942157.

13. Asai K, Kuzuya M, Naito M, Funaki C, Kuzuya F. Effects of splenectomy on serum lipids and experimental atherosclerosis. Angiology. 1988;39:497-504. PMID: 3377269.

14. Paulo DNS, Silva AL. Lipídeos plasmáticos após esplenectomia total e parcial em cães. Rev Col Bras Cir. 2001;28:264-70. doi: 10.1590/S0100-699120010004000006.

15. Paulo ICAL, Paulo DNS, Silva AL, Foletto RM, Colnago GL, Vargas PM. Níveis de lipides plasmáticos em ratos submetidos à esplenectomia total, ligadura simultânea dos vasos esplênicos e a esplenectomia subtotal com preservação do polo inferior. Rev Col Bras Cir. 2005;32:229-36. doi: 10.1590/S010069912005000500003.

16. Petroianu A, Veloso DFM, Costa GR, Alberti LR. Efeitos de operações sobre o baço no lipidograma de ratas. Rev Assoc Med Bras. 2006;52:56-9. PMID: 16622541.

17. Petroianu A, Neto JBR. Tratamento de hemorragia intestinal grave decorrente de hipertensão porta, por meio de esplenectomia subtotal e anastomose esplenorrenal proximal. Rev Col Bras Cir. 2008;35:264-8. doi: 10.1590/S0100-69912008000400010.

18. Petroianu A, Silva RG, Simal CJR, Carvalho DG, Silva RAP. Late postoperative follow-up of patients submitted to subtotal splenectomy. Am Surg. 1997;63:735-40. doi: 10.1590/S010442302002000100028.

19. Paulo MS, Santos FT, Rocha PG, Silva Mde B, Cintra LC, Motta LL, Errera FI, Paulo DN, Nunes TA. Immunoexpression of proliferating cell nuclear antigen (PCNA) in spleen of splenectomized rats with preservation of inferior pole, submitted to hyperbaric oxygenation. Acta Cir Bras. 2013;28(10):691-5. PMID: 24114296.

20. Petroianu A. Subtotal splenectomy for the treatment of chronic lymphocytic leukemia. Blood Cancer J. 2015 Mar 13;5:e289. doi: 10.1038/bcj.2015.16.

21. Chu H, Liu X, Zhao J, Xu Y, Wang L, Wang T, Guo W, Zhang S, Zhu $X$. Subtotal splenectomy for splenomegaly in cirrhotic patients. Int J Clin Exp Pathol. 2014;7(8):4981-90. PMID: 25197369.

22. Paulo DNS, Silva AL, Cintra LC, Bof AM, Santiago DC, Ribeiro GB. Esplenectomia subtotal, em cães, com preservação do polo inferior suprido por vasos do ligamento gastroesplênico. Rev Col Bras Cir. 1999;26:147-52. doi: 10.1590/5010069911999000300005.

23. Borjaili AS, Cerqueira BS, Silbermann JR, Rezende CF, Freire Júnior DD, Castello JS, Lenz D, Paulo DN, Nunes TA. Phagocytic function of lower spleen pole and autogenous splenic implants in rats. Acta Cir Bras. 2014;29(12):781-6. doi: 10.1590/S0102-86502014001900003.

24. Marques RG, Petroianu A, Portela JMCO, Crisóstomo M. Morfologia e função fagocitária de implante esplênico autógeno regenerado em ratos. Acta Cir Bras. 2004;19:642- 8. doi: 10.1590/ S0102-86502004000600011

25. Paulo DNS, Paulo ICAL, Kalil M, Vargas PM, Lázaro da Silva A, Baptista JFA, Guerra AJ. Subtotal splenectomy preserving the lower pole in rats: technical, morphological and functional aspects. Acta Cir Bras. 2006;21:321-7. doi: 10.1590/S0102865020060005000009 .

26. Silva JJ, Silva AL, Paulo DNS. Subtotal laparoscopic splenectomy in rats with preservation of the inferior pole. Acta Cir Bras. 2011;26:44-50. PMID: 21271203.
27. Paulo MSL, Paulo ICAL, Nunes TA, Silva AL, Cintra LC, Paulo DNS. Effect of hyperbaric oxygen therapy in rats with subtotal splenectomy preserving the inferior pole. Acta Cir Bras. 2010;26:156-8. doi: 10.1590/S0102-80502011000300002.

28. Torres OJM, Macedo EL, Picciani ERG, Nunes PMS, Costa JVG, Carvalho AB, Lobato Jr PS. Histological study of splenic regeneration in rats underwent to subtotal splenectomy. Acta Cir Bras. 2000;15(2):1-12. doi: 10.1590/S0102-8650.20000002000006.

29. Paulo ICAL, Paulo DNS, Ferrari TA, Azeredo TCV, Silva AL. O polo inferior do baço de ratos e a oxigenoterapia hiperbárica. Rev Assoc Med Bras. 2008;54:00. doi: 10.1590/S0104-423002008000100025.

30. Holmdahl L, Risberg B, Beck DE, Burns JW, Chegini N, diZerega GS, Ellis H. Adhesions: pathogenesis and prevention-panel discussion and summary. Eur J Surg Suppl. 1997;(577):56-62. PMID: 9076453.

\section{Acknowledgements}

To Marcela Souza Lima, Paulo, Luiz Antônio de Oliveira, Roberta Miranda de Araújo Mendes and Marcos Vinícius Gumiero for their technical support during the development of the study in the Laboratory of Animal Experimentation of EMESCAM.

\section{Correspondence:}

Tarcizo Afonso Nunes

Rua Professor Estevão Pinto, 637/1104

30220-060 Belo Horizonte - MG Brasil

Tel.: (55 31)3409-9632 / 9983-0110

tan@medicina.ufmg.br

Received: March 08, 2015

Review: May 10, 2015

Accepted: June 15, 2015

Conflict of interest: none

Financial source: none

${ }^{1}$ Research performed at Laboratory of Animal Experimentation, ICALP, Research Center, College of Health Sciences (EMESCAM), Vitoria-ES, Brazil. Part of Master degree thesis, Postgraduate Program in Surgical and Ophthalmological Applied Sciences, Universidade Federal de Minas Gerais (UFMG). Tutor: Tarcizo Afonso Nunes. 